\title{
Applying of hygroscopic materials to dry transformer insulation
}

\author{
Mateusz Cybulski ${ }^{1}$, Piotr Przybylek ${ }^{1, *}$ \\ ${ }^{1}$ Poznan University of Technology, Institute of Electric Power Engineering, Piotrowo 3A, 60-965 Poznan, Poland
}

\begin{abstract}
The problems related to the effects of high moisture content in the transformer insulation system and the risk resulting from the need for its immediate drying can be avoided by using a non-invasive method of continuous drying of solid insulation by means of high hygroscopic sorbents. The article compared the hygroscopicity of selected sorbents: molecular sieves $3 \mathrm{~A}, 5 \mathrm{~A}$ and $13 \mathrm{X}$, aluminum oxide and silica gel. It was found that the highest hygroscopicity, for a low value of relative air humidity, is characterized by a $13 \mathrm{X}$ molecular sieve. For this reason, this material was selected for further testing by checking its ability to dry mineral oil.
\end{abstract}

\section{Introduction}

Power transformers are one of the most important elements of the power system. Their reliable operation affects on the stability of the electricity transmission and distribution systems. The lifetime of transformer is closely related to the lifetime of its insulation system, which largely depends on the moisture content in transformer's insulation [1,2].

Three basic reasons for the presence of water in the transformer insulation system can be distinguished:

- residual moisture, which has not been removed at the stage of manufacturing a transformer,

- penetration of moisture from the atmosphere,

- material aging - especially cellulose oxidation [3].

Currently, there are several methods of drying cellulose transformer insulation at the place of its installation. The first group of methods use vacuum drying supported by various techniques of insulation heating, and the second group are based on drying transformer's insulation system by means of electroinsulating liquid. Drying of the insulation system by the electro-insulating liquid is based on the phenomenon of water migration from cellulose material with higher relative humidity to the insulating liquid with lower relative saturation. The continuity of the process can be ensured by drying the oil using a high hygroscopic sorbent.

The method of drying cellulose insulation by means of electro-insulating liquid is much less efficient than the vacuum method [4], nevertheless it is much less invasive for the insulation system, and therefore more secure.

Drying the electro-insulating liquid by means of a sorbent can be used to maintain a low level of water content in oil-paper insulation throughout entire lifetime of transformer.

\section{Hygroscopicity of sorbents in the aspect of their use to dry electro- insulating liquid}

\subsection{Comparison of hygroscopicity of selected sorbents}

The aim of the study was to compare the water content in sorbents conditioned in the air under strictly defined relative humidity and temperature and select the material characterized by the highest hygroscopicity. Several sorbents were selected for the study, which according to the literature, show high hygroscopicity and could be used as a material for drying electro-insulating liquids, and indirectly also for drying the transformer's cellulose insulation. The following materials were chosen: 3A, 5A and $13 \mathrm{X}$ molecular sieves, aluminum oxide and silica gel.

The ability of the above mentioned materials to water sorption was checked using a saturated salt solution of cesium fluoride $\left(\mathrm{RH}=2.69 \%, \mathrm{~T}=35^{\circ} \mathrm{C}\right)$ [5]. The water content in the investigated sorbents was determined by the gravimetric method. The research results are presented in Figure 1.

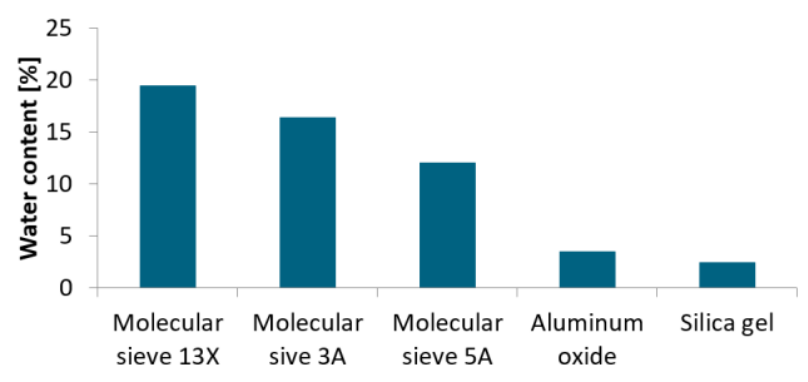

Fig. 1. Comparison of water content in selected materials conditioned in the air of $\mathrm{RH}=2,69 \%$ and $\mathrm{T}=35^{\circ} \mathrm{C}$.

* Corresponding author: piotr.przybylek@put.poznan.pl 
The conducted experiment allowed for the selection of a sorbent characterized by the highest hygroscopicity for the assumed experimental conditions. Among the analyzed materials, the highest water absorption capacity was found in the $13 \mathrm{X}$ molecular sieve, where the final water content was equal to $19.45 \%$. For this reason, this material was selected for further research.

\subsection{Application of $13 \mathrm{X}$ molecular sieve to dry mineral oil}

The scheme of measurement system used to evaluation of the possibility of drying mineral oil by means of $13 \mathrm{X}$ molecular sieve is shown in Figure 2.

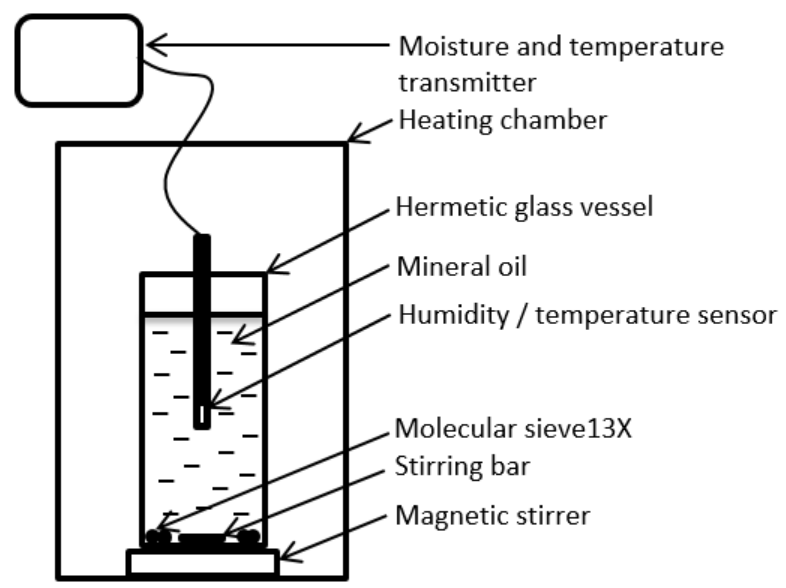

Fig. 2. Scheme of the measurement system for testing the water content in mineral oil during its drying by means of the molecular sieve $13 \mathrm{X}$.

The drying of mineral oil was carried out in a sealed glass vessel with a volume of one liter. $850 \mathrm{ml}$ of oil were poured into the vessel. The measurements of the relative saturation of water in oil $(R S)$, water content in oil $(W C O)$ and oil temperature $\left(T_{o}\right)$ were carried out using a probe equipped with a capacitive and temperature sensors. To eliminate the influence of temperature on the results of relative saturation, the measuring system was placed in a heating chamber. The oil temperature was maintained at $35^{\circ} \mathrm{C}$. First the system was conditioned for $24 \mathrm{~h}$ to achieve thermodynamic equilibrium $\left(\mathrm{RS}=26.5 \%, \quad \mathrm{~T}_{\mathrm{o}}=35^{\circ} \mathrm{C}\right)$. Subsequently, dried 13X molecular sieve with a mass of $0.1077 \mathrm{~g}$ was added to the oil. The sieve mass, needed to completely dry the oil, was calculated on the basis of the results shown in Figure 1 and the weight of water in oil before drying $(0.0174 \mathrm{~g})$. Figure 3 shows the results recorded by means of measuring probe during oil drying.

Analyzing the results presented in Figure 3, it can be noticed that the obtained drying effect was differ from the expected result calculated from the determined ability of the $13 \mathrm{X}$ molecular sieve to adsorb water from the air. After the drying process the relative saturation of the oil was stabilized at $9.6 \%$, and thus it was not possible to completely dry the oil. A weighted amount of sorbent was enough to adsorb $0.011 \mathrm{~g}$ of water from the oil.

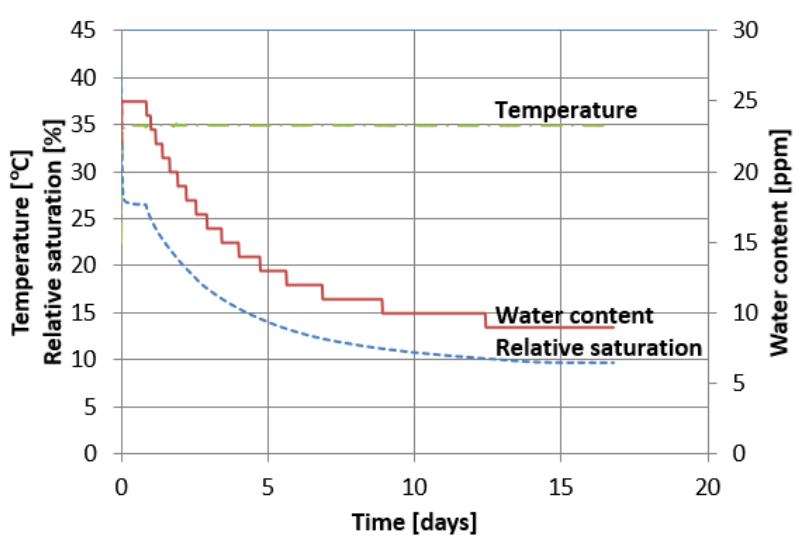

Fig. 3. The relative saturation of water in oil, water content in oil and oil temperature during drying of oil by means of molecular sieve.

The discrepancy between the expected drying result and the obtained effects may be related to the presence of dissolved gases in the oil. If the diameter of the gas molecule is smaller than the pore diameter of the molecular sieve, which in the case of the $13 \mathrm{X}$ molecular sieve is $9 \AA$, then these particles will also be able to penetrate its crystalline structure, which may cause the decrease of their hygroscopicity. Therefore, further research of sorption selectivity of various sieves are necessary. Nevertheless, it should be noted, that the ability of the $13 \mathrm{X}$ molecular sieve to dry the oil is very high.

\section{Conclusions}

The article indicates sorbents that show high hygroscopicity and could be used as a material for drying electro-insulating liquids, and indirectly also for drying cellulose insulation. Using the saturated salt solution of cesium fluoride, the hygroscopicity of $3 \mathrm{~A}$, 5A and 13X molecular sieves, alumina and silica gel was compared. On the basis of the conducted research, the material with the highest water sorption capacity was indicated. This material is the $13 \mathrm{X}$ molecular sieve. The measurements confirmed the high potential of the molecular sieves for their application to dry insulation systems of power transformers. It should be noted that further research are necessary, especially in the context of drying efficiency by means of molecular sieve and operational safety of such dried transformers.

\section{References}

1. J.S. N'cho, I. Fofana, Y. Hadjadj, A. Beroual, Energies 9(5), 367 (2016)

2. P. Przybylek, IEEE Trans. Dielectr. Electr. Insul. 23, 1886-1893 (2016)

3. Brochure, Cigre, 349 (2008)

4. P. Koestinger, E. Aronsen, P. Boss, G. Rindlisbacher, Cigre, A2-205 (2004)

5. L. Greenspan, J. Res. Natl. Bur. Stand. 81A (1977) 